Ana Carolina Hungria Xavier ${ }^{1}$

Carla Regina Veiga Barcelos ${ }^{1}$

Jaqueline Peixoto Lopes ${ }^{1}$

Priscila Gandarela Chamarelli

Sarah de Souza Ribeiro ${ }^{1}$

Luciene da Silva Lacerda²

Marisa Palacios ${ }^{2}$

\section{Assédio moral no trabalho no setor saúde no Rio de Janeiro: algumas características}

\author{
Workplace moral harassment in Rio de Janeiro health sector - \\ some characteristics
}

\author{
${ }^{1}$ Faculdade de Medicina da Universida- \\ de Federal do Rio de Janeiro. \\ ${ }^{2}$ Instituto de Estudos em Saúde Cole- \\ tiva da Universidade Federal do Rio de \\ Janeiro. \\ Contato: \\ Marisa Palacios \\ Rua Conde de Baependi, 59/702 \\ Rio de Janeiro-RJ \\ CEP: 22231-140 \\ E-mail: \\ marisa.palacios@globo.com \\ Apoio financeiro: \\ Organização Internacional do Trabalho
}

Recebido: 06/08/07

Revisado: 31/01/08

Aprovado: 03/03/08

\section{Resumo}

Este artigo objetiva analisar a magnitude e algumas características do fenômeno do assédio moral no trabalho no setor saúde do Rio de Janeiro. Foram analisados dados de pesquisa desenvolvida em 2001 como parte do programa "Violência no Trabalho no Setor Saúde”, resultantes de um inquérito anônimo. Para constituir o banco para análise, foram selecionados todos os casos (1.569) e as variáveis relacionadas ao assédio moral.

O grupo profissional que teve maior proporção de vítimas de assédio moral foi o de auxiliar de enfermagem (22,7\%). Colegas, supervisores ou administradores compuseram o mais importante grupo de agressores $(48,7 \%)$. A reação psicológica mais prevalente foi "permanecer supervigilante". Embora 38,5\% das vítimas tenham relatado a violência a superiores, $20 \%$ relataram ter sido tomada alguma providência. Os autores concluem que mais pesquisas e medidas de vigilância devem ser realizadas no Brasil para assegurar a visibilidade desse tipo de violência. Além disso, ressaltam a necessidade de implementar medidas institucionais de controle da violência no trabalho e de estimular estudos que enfatizem o manejo institucional desse tipo de violência.

Palavras-chaves: assédio moral, condições de trabalho, violência, trabalho, saúde do trabalhador.

\begin{abstract}
This article aims at analyzing the magnitude and some characteristics of the workplace moral harassment phenomenon in Rio de Janeiro health sector. Data from a randomized anonymous survey research developed in 2001 as part of the Program "Workplace Violence in the Health Sector" was analyzed. All cases (1569) and their variables related to moral harassment were selected for the bank analysis. The professional group of nurses' aides presented the highest proportion of moral harassment victims (22.7\%) and the most frequent perpetrators were co-workers, supervisors and managers (48.7\%). The victims' most frequent psychological reaction was "becoming super-alert". Although part of them (38.5\%) reported to their bosses they had been morally harrassed, only $20 \%$ of them had an action taken. In order to evidence this kind of violence in Brazil, the authors suggest increasing research and surveillance. They also emphasize the need to implement institutional measures to control violence at work and studies that will stimulate the institutional management of this kind of violence.
\end{abstract}

Keywords: moral harassment, mobbing, working conditions, violence, work, occupational health. 


\section{Introdução}

Violência no trabalho é definida como incidentes em que o trabalhador sofre abuso, ameaça ou ataque em circunstâncias relacionadas ao seu trabalho, inclusive no trajeto de ida e volta ao mesmo, envolvendo ameaça explícita ou implícita para sua segurança, bem-estar ou saúde (ILO; ICN; WHO; PSI, 2002). A violência no trabalho, segundo esse documento, foi classificada como violência física, definida como o uso de força física contra outra pessoa ou grupo, que resulta em malefício físico, sexual ou psicológico, e violência psicológica, expressa pelo uso intencional do poder, incluindo ameaça de força física contra outra pessoa ou grupo, que pode resultar em malefício para o desenvolvimento físico, mental, espiritual, moral ou social, apresentando quatro subtipos: agressão verbal, assédio moral, assédio sexual e discriminação racial.

No âmbito do programa "Violência no Trabalho no Setor Saúde”, empreendido pela Organização Internacional do Trabalho, pelo Conselho Internacional de Enfermagem, pela Organização Mundial da Saúde e pela Internacional de Serviços Públicos, foi realizada uma pesquisa no Rio de Janeiro em 2002. Essa pesquisa apontou que, do total de trabalhadores de saúde analisados, 46,7\% informaram ter sofrido pelo menos uma agressão no último ano. Tomando todos os trabalhadores, 6,4\% informaram ter sofrido agressão física, 39,5\% agressão verbal, 15,2\% assédio moral, 5,7\% assédio sexual e 5,3\% discriminação racial no último ano (PALÁCIOS et al., 2002). Esse estudo foi pioneiro e mostrou a magnitude do fenômeno da violência no trabalho no Brasil.

Neste trabalho, nosso foco central é o assédio moral, uma vez que é um tipo de violência que tem participação majoritária de colegas e chefes como perpetradores, alta prevalência e graves conseqüências para os trabalhadores assediados e para o ambiente de trabalho (PALÁCIOS et al., 2002). Ele foi definido neste estudo como comportamento ofensivo, humilhante, que desqualifica ou desmoraliza, repetido e em excesso, através de ataques vingativos, cruéis e maliciosos, que objetiva rebaixar um indivíduo ou grupo de trabalhadoras/es.

O primeiro estudo sobre o fenômeno "assédio moral” foi conduzido nos anos 1980 pelo sueco Heinz Leymann, que o denominou mobbing:

[...] como o fenômeno no qual uma pessoa ou grupo de pessoas exerce violência psicológica extrema, de forma sistemática e recorrente e durante um tempo prolongado [...] sobre outra pessoa no local de trabalho, com a finalidade de destruir as redes de comunicação da vítima ou vítimas, destruir sua reputação, perturbar a execução de seu trabalho e conseguir, finalmente, que essa pessoa ou pessoas acabem abandonando o local de trabalho. (LEYMANN, 1990 apud GUIMARÃES; RIMOLI, 2006, p. 184)
Esse mesmo fenômeno tem sido descrito em todo o mundo com terminologia diversa. Em linhas gerais, cada país adotou um termo para referir-se ao fenômeno: na Suécia e na Inglaterra, mobbing, nos EUA, bullying e harassment; na Espanha, psicoterror ou acoso moral; na França, harcèlement moral, no Japão, Ijim e no Brasil, assédio moral (SCANFONE; TEODÓSIO, 2004).

No Brasil, o conceito de assédio moral no trabalho começa a ganhar as páginas das revistas de grande circulação fora do meio acadêmico a partir do lançamento do livro de Hirigoyen (2000), que discute o assédio moral na família e no trabalho. Define-o como:

[...] uma conduta abusiva (gestos, palavras, comportamentos, atitudes...) que atente, por sua repetição ou sistematização, contra a dignidade ou integridade psíquica ou física de uma pessoa, pondo em perigo sua posição de trabalho ou deteriorando o ambiente de trabalho. (p. 13)

Essa autora tipifica o assédio moral em: assédio vertical descendente, parte do superior para o subordinado; assédio horizontal, parte de colegas do mesmo nível hierárquico na empresa, sendo mais freqüentemente encontrado quando dois empregados disputam o mesmo cargo ou uma promoção; assédio misto, por mais de um tipo de assediador, descendente, horizontal, ascendente; assédio ascendente, por um ou mais subordinados a um superior. No Brasil, pesquisa pioneira realizada por Barreto (2000) constatou que $42 \%$ dos trabalhadores entrevistados foram vítimas de assédio moral nas empresas. Essa autora definiu assédio moral como:

[...] uma exposição dos trabalhadores e trabalhado-
ras a situações humilhantes e constrangedoras, repe-
titivas e prolongadas durante a jornada de trabalho
e no exercício de suas funções, sendo mais comuns
em relações hierárquicas autoritárias e assimétricas,
em que predominam condutas negativas, relações
desumanas e éticas de longa duração, de um ou
mais chefes dirigida a um ou mais subordinado(s),
desestabilizando a relação da vítima com o ambien-
te de trabalho e a organização, forçando-o a desistir
do emprego. (BARRETO, 2004)

O assédio moral no ambiente organizacional se apresenta de forma variada, podendo ter como conseqüências sobre os trabalhadores desde acidentes físicos a sofrimentos psíquicos. Assediados podem apresentar desânimo, cansaço, ansiedade, estresse, tendência suicida, insegurança, vergonha e hipersensibilidade. Para as organizações, o assédio pode causar baixa produtividade, diminuição de benefícios, maiores custos de seleção e formação de pessoal substituto; para o governo, acarreta gastos com a saúde do trabalhador (OIT, 2000).

O objetivo deste estudo é caracterizar o assédio moral no setor saúde do Rio de Janeiro no que diz respeito às vítimas, aos agressores, ao grau de satisfação e incômodo. 


\section{Materiais e métodos}

Os dados da pesquisa foram levantados por meio de um inquérito confidencial com questionário padronizado, respondido por 1.569 profissionais de saúde, na cidade do Rio de Janeiro.

Para o cálculo e a distribuição da amostra, foram utilizados dados da pesquisa sobre Assistência Médico-Sanitária (AMS) de 1999, realizada pelo IBGE (1999). Foi utilizado um processo de amostragem em três tempos. Inicialmente, os estabelecimentos de saúde foram estratificados em oito grupos, segundo as seguintes características: com ou sem internação; gerais ou especializados; públicos ou privados. De cada grupo foram selecionadas algumas unidades de saúde típicas, de acordo com o consenso da equipe: um hospital universitário; um hospital geral federal; um hospital de emergência (3 unidades de saúde com internação); 2 hospitais públicos especializados; 2 centros de saúde municipais e um posto de saúde comunitário (3 estabelecimentos públicos sem internação); 3 unidades privadas com internação; 2 estabelecimentos privados especializados com internação; 1 estabelecimento de saúde especializado sem internação; unidades ambulatoriais privadas. Foram incluídas quatro equipes de ambulância do corpo de bombeiros.

No segundo tempo, para cada grupo de estabelecimentos, foi calculado, de acordo com os dados da AMS do IBGE (1999), o número de trabalhadores da saúde, estratificados em três grupos de acordo com o nível de qualificação: universitário, técnico ou elementar e administrativo. Como resultado desta etapa, foi elaborada a distribuição por estabelecimento do quantitativo de profissionais de cada estrato.

No terceiro estágio, foi feita a distribuição da amostra da seguinte maneira: de cada estabelecimento, foi recebida uma lista de trabalhadores, incluindo o local onde eles trabalhavam e a categoria profissional, independentemente do vínculo de trabalho com a instituição; em cada estrato de nível de qualificação foram calculados os números de representantes de cada categoria profissional, proporcional a sua distribuição na unidade de saúde, garantindo que todos os cargos, setores e categorias profissionais fossem contemplados. Em cada estabelecimento de saúde, os entrevistadores seguiram os seguintes procedimentos:

1 - distribuição, para todos os trabalhadores, de carta explicativa dos objetivos da pesquisa, todos os seus procedimentos, relevância, riscos e benefícios;

2 - negociação com a direção do estabelecimento de local e horário para realização das entrevistas;

3 - não foi solicitada a assinatura de termo de consentimento, uma vez que havia tanto na carta distribuída, quanto na folha de rosto do questionário uma explicação detalhada da pesquisa e uma garantia de compromisso da equipe quanto à confidencialidade dos dados e quanto ao retorno dos dados para os sujei- tos da pesquisa (admitiu-se que a assinatura do termo iria identificar os respondentes);

4 - após garantir que o trabalhador tivesse lido a carta distribuída e a folha de rosto do questionário, ele era solicitado a preencher o formulário caso concordasse em participar. O entrevistador aguardava, então, a seu lado ou lia o questionário quando solicitado pelo trabalhador.

O projeto foi aprovado pelo Comitê de Ética do IESC-UFRJ e pela Comissão Nacional de Ética em Pesquisa (CONEP), uma vez que se tratava de um estudo multicêntrico.

\section{O instrumento}

O questionário era auto-aplicável, composto por perguntas com opções fechadas de respostas e possuía cinco divisões: bloco A, com perguntas sobre dados pessoais (sociodemográficos); B, violência física no local de trabalho; $\mathrm{C}$, violência psicológica, que se subdivide em: C I, agressão verbal; C II, intimidação/ assédio moral; C III, assédio sexual; e C IV, discriminação racial; D, contendo perguntas sobre medidas para lidar com a violência no local de trabalho; e E, sobre opinião do indivíduo sobre o local de trabalho, que, diferentemente do restante do questionário, possuía três perguntas abertas.

Neste artigo, somente serão trabalhados os dados relativos ao assédio moral e a algumas variáveis demográficas, como sexo e qualificação profissional. Inicialmente, é preciso esclarecer que ter sido vítima de assédio moral é uma informação obtida através de uma pergunta direta ao sujeito da pesquisa, que informa sim ou não. A partir dessa informação, o sujeito era solicitado a responder um conjunto de perguntas para caracterização das condições em que ocorreu o assédio dos agressores, de suas reações e conseqüências. No presente artigo, selecionamos os dados dos 1.425 trabalhadores que responderam ao bloco C II (intimidação/assédio moral) do questionário.

\section{Limites}

É importante destacar que, embora a amostra tenha sido selecionada segundo os critérios expostos acima, garantindo a representação da população de profissionais de saúde lotados na cidade do Rio de Janeiro, o número limitado de estabelecimentos pode ter introduzido algum viés.

\section{Resultados e Discussão}

\section{A magnitude do fenômeno e sua invisibilidade}

Dos 1.425 trabalhadores que responderam à subdivisão CII do questionário sobre o assédio moral, 963 
eram mulheres e 462 eram homens. Das 963 mulheres, $16,2 \%$ responderam já ter sido vítima de assédio moral, e dos 462 homens, 18,0\% deram uma resposta afirmativa a essa questão.

Cezar e Marziale (2006), estudando a violência entre trabalhadores de saúde em uma emergência, sem considerar o tipo de violência, encontraram associação entre violência e sexo semelhante aos achados do estudo aqui apresentado, constatando que homens $(92,3 \%)$ sofreram mais violência ocupacional que mulheres (85,7\%). Esses dados, como observam os autores, contrariam uma expectativa formada a partir dos estudos de violência em geral, que apontam para uma maior vulnerabilidade das mulheres à violência. Note-se que, no referido estudo, a freqüência de vítimas de violência é muito maior, tendo em vista que esses autores trabalharam com todo tipo de violência e ainda não se restringiram ao último ano, como em nosso estudo.

Uma pergunta que pode ser feita é se a maior prevalência de violência entre os homens se deve ao fato de, nos estabelecimentos de saúde, os homens serem minoria. O que se ajustaria à idéia de que a violência tem como substrato fundamental a negação do outro, seu não reconhecimento, o que é freqüentemente relacionado às minorias (étnicas, de gênero etc.) objeto de discriminação.

Outra pergunta é se a medida de freqüência por toda vida seria superior à encontrada em nossa pesquisa, ocultando assim, ainda mais, parte da magnitude desse fenômeno. Embora os números sejam bastante significativos, não há registro oficial, seja em termos de vigilância em saúde do trabalhador, seja na área de gerência de pessoal. O assédio moral é uma epidemia invisível. Essa invisibilidade traz como conseqüência a não mobilização de recursos de todas as naturezas para o combate à violência e a adoção de medidas de prevenção. O que acontece com o assédio moral é que a conseqüência sobre a saúde mental, como demonstram vários estudos, especialmente o de Soboll (2007), é de tal ordem que pode marcar negativamente e de maneira definitiva a vida laboral ou mesmo toda a vida de relação da pessoa assediada, o que faz com que medidas de prevenção sejam necessárias e urgentes.

\section{Quem são os agredidos?}

Dentre todas as categorias profissionais que responderam ao questionário, a de auxiliar de enfermagem apresentou a maior freqüência de vítimas desse tipo de violência. Desse grupo, 22,7\% afirmaram ter sofrido assédio moral no último ano, seguido pelos enfermeiros (21,5\%). Dentre os médicos, 15,1\% informaram ter sofrido assédio moral (Tabela 1).

Cezar e Marziale (2006), embora não tenham estudado o assédio moral seletivamente, encontraram resultados semelhantes aos nossos quanto à caracterização das vítimas de violência ocupacional. As autoras mostraram que os enfermeiros foram os que mais sofreram violência, seguidos dos auxiliares de enfermagem e dos médicos. É interessante que esses dados revelam as relações de poder nos estabelecimentos de saúde, especialmente considerando a violência como na definição da Organização Mundial da Saúde (OMS, 1996), que estabeleceu a violência como prioridade para a saúde pública e ao abuso de poder. Os enfermeiros, como categoria, encontram-se em situação intermediária entre o médico e os auxiliares. Em estabelecimentos de saúde, há uma clara linha de mando, embora nem sempre esteja traduzida na hierarquia formal das organizações, em que médicos ocupam o topo, seguidos pelos enfermeiros, e os auxiliares, em maior número, estão entre os que cumprem as ordens. Assim, podemos nos perguntar se o maior percentual de assédio no grupo de enfermeiros, semelhante ao percentual dos auxiliares, poderia ser atribuído a uma maior disputa de poder, levando a conflitos mais freqüentes entre profissionais de nível superior.

Tabela 1 Vítimas de assédio moral de acordo com categoria profissional

\begin{tabular}{lccccc}
\hline & \multicolumn{5}{c}{ Assédio moral } \\
& \multicolumn{2}{c}{ Sim } & \multicolumn{2}{c}{ Não } & Total \\
& $N$ & $\%$ & $N$ & $\%$ & \\
\hline Auxiliar & 69 & 22,7 & 235 & 77,3 & 304 \\
Enfermeiro & 20 & 21,5 & 73 & 78,5 & 93 \\
Administração & 35 & 19,4 & 145 & 80,6 & 180 \\
Outros & 22 & 17,5 & 104 & 82,5 & 126 \\
Técnicos - nível médio & 16 & 17,0 & 78 & 83,0 & 94 \\
Médicos & 44 & 15,1 & 248 & 84,9 & 292 \\
Técnicos - nível elementar & 23 & 13,9 & 143 & 86,1 & 166 \\
Técnicos - nível superior & 11 & 6,4 & 160 & 93,6 & 171 \\
\hline
\end{tabular}




\section{Quem são os agressores?}

Quanto à caracterização dos agressores, nossos resultados mostraram que $48,7 \%$ dos agredidos moralmente relataram ter sido vítimas de seus colegas de trabalho (colegas de trabalho, colegas de trabalho externo e chefe, totalizando 115 respondentes). Dos profissionais que relataram ser vítimas de assédio, $44,1 \%(\mathrm{~N}=104)$ apontaram como agressores o grupo constituído por pacientes, parentes ou público em geral, os que são os beneficiários do serviço prestado por esses trabalhadores. Se corrigirmos esse dado tomando somente os trabalhadores que interagem com pacientes, dos 217 trabalhadores que sofreram assédio moral desse grupo, no último ano, 101 (46,5\%) foram assediados por esse grupo de beneficiários dos serviços. Dos entrevistados, $7,2 \%(\mathrm{~N}=17)$ relataram ter sido vítimas de outros agressores.

Kwok et al. (2006), em seu estudo sobre a prevalência de assédio moral em enfermeiras de Hong Kong, verificou que os maiores perpetradores de agressões, segundo as informações das vítimas, eram os pacientes e seus acompanhantes, seguidos por colegas de profissão.

As agressões dos pacientes ou de seus parentes podem estar relacionadas às más condições de trabalho e atendimento. Um paciente angustiado pela doença e frustrado com um atendimento sem recursos está mais suscetível a agredir. Mas, mesmo assim, quanto ao assédio moral, ainda nos faltam explicações e talvez um estudo qualitativo que pudesse nos apontar pistas.

\section{Reação da vítima}

Quanto à caracterização da reação da vítima à agressão, o questionário apresentou aos respondentes um inventário de possibilidades, as mais freqüentemente encontradas na literatura científica. Os resultados mostram que a maioria das vítimas $(38,49 \%)$ teve como reação à violência sofrida relatar o ocorrido a seu chefe, mas um número significativo de vítimas $(27,2 \%)$ não esboçou nenhuma reação (Gráfico 1$)$.

Diferentemente dos nossos resultados, Bilgel (2006), estudando a prevalência de bullying no local de trabalho de três setores da cidade de Bursa (Turquia) - saúde, educação e segurança -, verificou que, em resposta ao assédio moral, a maioria das vítimas relatavam o ocorrido a um colega ou ignoravam seu perpetrador. A opção de relatar ao chefe indica uma esperança de que alguma medida poderá ser tomada para minorar o sofrimento ou impedir que as agressões se perpetuem. É bom notar que em nenhum es-

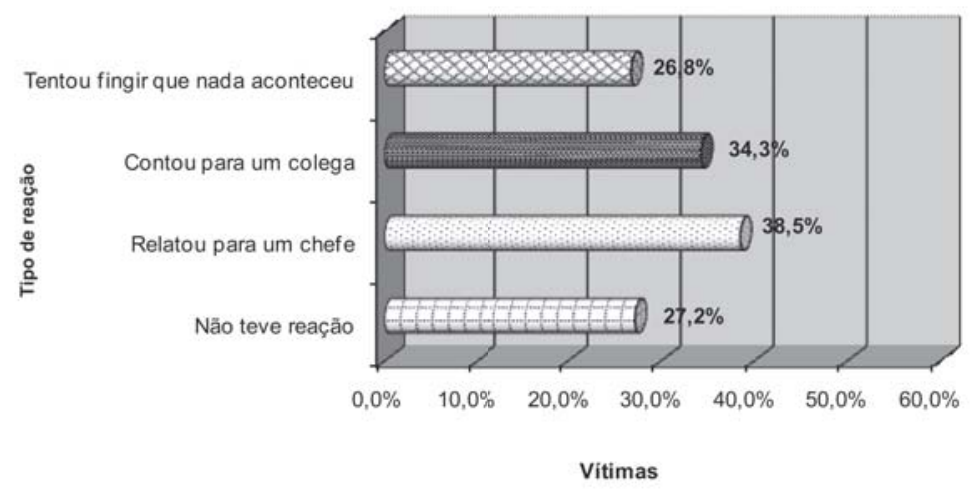

Gráfico 1 Reação das vítimas de assédio moral

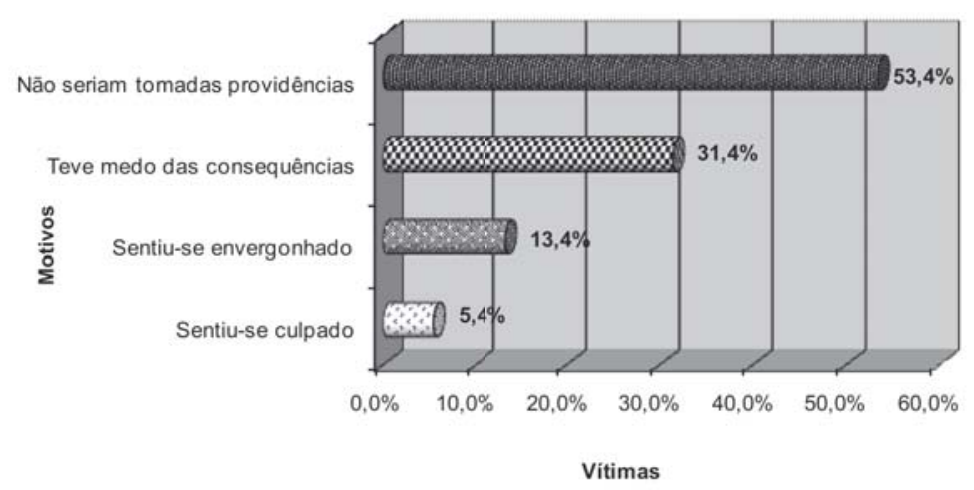

Gráfico 2 Motivos pelos quais não houve relato das vítimas 
tabelecimento havia registro formal para os casos de violência, tampouco protocolo de procedimentos para tratar dos casos (apuração, acolhimento, tratamento ou qualquer outro procedimento).

Quanto ao motivo de não relatar sobre o ocorrido, $53,4 \%$ responderam não acreditar que alguma providência seria tomada (Gráfico 2). Mesmo daqueles que tomaram a iniciativa de relatar aos chefes $(\mathrm{N}=94)$, somente $20 \%$ relataram ter sido tomada alguma providência. Mas, quanto a se sentirem culpados ou envergonhados pelo fato ocorrido, a maioria não identificou essas assertivas como razões de não relato (Gráfico 2).

O grau de satisfação dos assediados com a forma como foi tratado o incidente expressa a necessidade de tratar da questão da violência, especialmente o assédio moral, como importante fator de insatisfação dos trabalhadores. Das vítimas, 51,4\% estavam muito insatisfeitas e apenas $8,6 \%$ estavam muito satisfeitas com o tratamento que seu caso recebeu (Gráfico 3).

Quanto às conseqüências psicológicas relacionadas ao assédio, os trabalhadores foram solicitados a responder numa escala de 1 a 5 quão incomodados estavam por: (a) memórias, pensamentos ou imagens da agressão repetidas e perturbadoras; (b) evitar pen- sar ou falar sobre a agressão ou evitar sentimentos relacionados à mesma; (c) permanecer "super-alerta", vigilante, de sobreaviso ou constantemente tenso(a); (d) sentimento de que suas atividades passaram a ser mais penosas.

Os resultados mostram que a tensão, um estado de permanente vigilância, é a conseqüência mais freqüente e de maior intensidade (Tabela 2).

Os dados de reação, assim como as conseqüências psicológicas da agressão, ainda precisam de estudos qualitativos que dêem sentido aos dados: como caracterizar que o assédio moral seja horizontal, vertical ou praticado pelos beneficiários dos serviços prestados? Não há ou há pouco sofrimento entre aqueles que se identificaram como vítimas de assédio moral? Ou os indicadores utilizados na pesquisa foram inadequados ou insuficientes?

\section{Quais fatores ou situações contribuem para a ocor- rência de assédio moral no trabalho de trabalhado- res de saúde?}

Algumas questões emergem dos resultados da pesquisa. E aqui é necessário distinguir dois tipos de

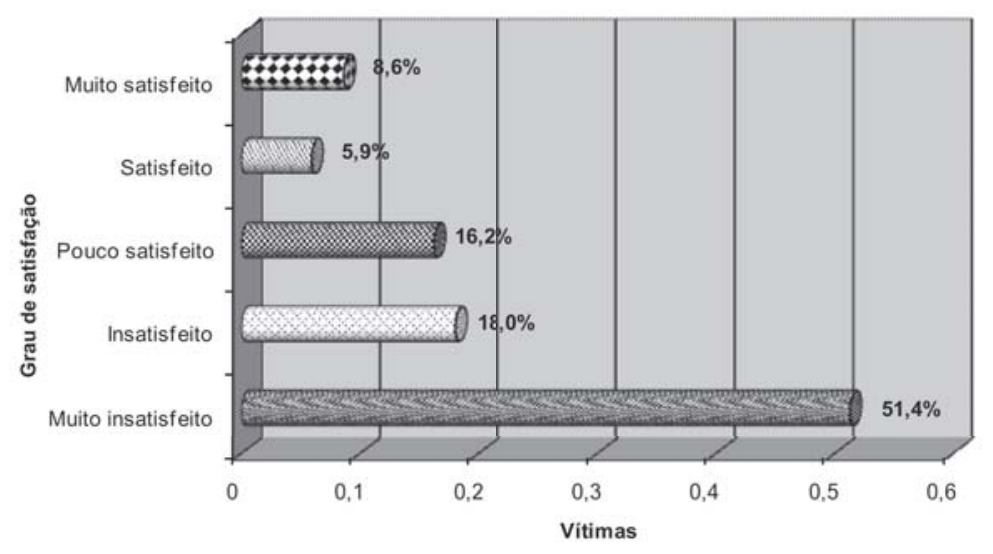

Gráfico 3 Grau de satisfação com a forma de tratamento do incidente

Tabela 2 Conseqüências psicológicas para as vítimas

\begin{tabular}{lccccc}
\hline \multicolumn{1}{c}{ Conseqüencias psicológicas } & $N$ & Mínimo & Máximo & Média & Desvio padrão \\
\hline Memórias perturbadoras & 217 & 1 & 5 & 2,4 & 1,2 \\
Evitar pensar & 215 & 1 & 5 & 2,5 & 1,3 \\
Permanecer vigilante & 214 & 1 & 5 & 3,1 & 1,3 \\
Atividades tornaram-se penosas & 213 & 1 & 5 & 2,5 & 1,4 \\
\hline
\end{tabular}


assédio moral: segundo Peek-Asa, Runyan e Zwerling (2001), o que é perpetrado pelos beneficiários dos serviços que o trabalhador presta, caracterizado como violência de Tipo II, e o tipo III, que é perpetrado por colegas e chefes. Atendo-nos ao praticado por colegas e chefes, o que representa a maior parte do assédio moral ocorrido, segundo nossos dados, embora a pesquisa não nos tivesse permitido caracterizar melhor esse assédio, não podemos acreditar numa suposta natureza perversa do assediador como razão única para a ocorrência deste tipo de violência. É necessário encontrarmos na organização e no processo de trabalho em saúde os elementos centrais que estimulam um tipo de comportamento, ou melhor, um tipo de relação que possa levar à destruição de vidas humanas. Não é difícil pensarmos como hipótese que a reestruturação do setor saúde - com a precarização do vínculo de trabalho e o sucateamento de sua infra-estrutura pública por um lado e, por outro, as relações mercantis que movem o setor privado, seja através dos planos de saúde ou da prestação direta do serviço de saúde - possa levar as relações intersubjetivas a níveis extraordinários de competição, de negação do outro, o que é condição necessária para a ocorrência de violência. Retomamos a definição de violência dada por Tavares dos Santos, Nery e Simon (1999):

[...] excesso de poder que impede o reconhecimento do outro - pessoa, classe, gênero ou raça - mediante o uso da força ou da coerção, provocando algum tipo de dano, configurando o oposto das possibilidades da sociedade democrática contemporânea. (p. 15)

A referência à sociedade democrática revela o papel fundamental do diálogo, do respeito às pessoas, da negociação como forma de resolver os conflitos que ocorrem no âmbito das relações de trabalho. Zaluar e Leal (2001) chamam a atenção para a diferenciação entre conflito e violência: não há violência no conflito quando há negociação, na qual há manifestação da autonomia do sujeito e do respeito.

\section{O que fazer?}

Os dados da pesquisa mostram o quanto a invisibilidade da violência traz conseqüências: a reação mais comum é nem sequer relatar e, mesmo quando se relata ou se tenta registrar as ocorrências, não há conseqüência na maioria das vezes, porque não é um procedimento comum. Não há discussão sobre o assunto e cada um que é assediado é mantido isolado com seu sofrimento. Não há um caminho institucionalizado para resolução de casos de conflito. Na maioria de nossas instituições de saúde, não há espaços para discussão, para negociação e organização democrática dos serviços. O grau de insatisfação que as vítimas demonstram com a maneira como seu caso foi tratado é também indicador da necessidade e da urgência em se encontrar as formas de manejo da violência e de implementação de práticas institucionais que vi- sem amparar e proteger os assediados e tratar quando for o caso. Combater essa invisibilidade nos parece o primeiro ponto a ser pretendido, seja com a proliferação de pesquisas sobre o tema, seja com estratégias, mesmo que localizadas por instituição, para garantir o registro no âmbito de programas de vigilância em saúde do trabalhador ou de manejo de conflito na área de gerência de pessoal.

Os países centrais têm tido algumas experiências quanto ao manejo da violência, mas, como pontuam LeBlanc e Barling (2004), ainda são necessários estudos que comprovem a eficácia das medidas de controle na prevenção da violência, especialmente a violência praticada por colegas e chefes (insiders), como a política de tolerância zero ou a teoria da janela quebrada (broken windows theory - HESKETH et al., 2003). A política de tolerância zero implica num compromisso institucional com a apuração de todo tipo de violência segundo um protocolo pré-estabelecido e inclui medidas educativas para estimular a identificação e a apuração. A teoria da janela quebrada é uma teoria desenvolvida na área de segurança e alguns autores canadenses (HESKETH et al., 2003) a trouxeram para a área da saúde. A abordagem baseada nessa teoria:

[...] requer uma resposta imediata e visível a todos os incidentes de violência, mesmo independentemente de quão inócuos possam parecer. (p. 320)

A idéia central dessa teoria é que atos de vandalismo, como quebrar a janela, quando não são devidamente tratados, constituem um caldo de cultura para ações criminosas de maior gravidade.

\section{Considerações finais}

A análise específica dos dados referentes ao assédio moral permitiu-nos uma visão mais clara sobre o assunto. Percebemos que esse tipo de violência atinge um número importante de trabalhadores, como podemos ver, não só nos nossos resultados, mas também em outros estudos que trouxemos para dialogar.

Dessa forma, pesquisas como esta devem ser levadas a cabo para que se possa chamar a atenção sobre o assunto, colocando-o em pauta de discussão e mesmo de negociação coletiva, como ponto importante do diálogo social no setor saúde.

Por fim, os dados aqui analisados foram colhidos em 2001, quando apenas se iniciava a divulgação do fenômeno assédio moral no trabalho. É digno de nota que, desde então, a situação dos serviços de saúde tem se agravado. Hoje, como a questão do assédio moral está muito mais divulgada pela mídia, talvez possamos encontrar maior freqüência desse tipo de violência por conta do maior reconhecimento do problema. 


\section{Referências}

BARRETO, M. Violência, saúde e trabalho: uma jornada de humilhações. São Paulo: EDUC, 2000.

BARRETO, M. O que é assédio moral, 2004.

Disponível em: http://www.assediomoral.org/site/ assedio/AMconceito.php. Acesso em: maio 2007.

BILGEL, N.; AVTAC, S.; BAYRAM, N. Bullying in Turkish white-collar workers. Occupational Medicine, v. 56, p. 226-231, 2006.

CEZAR, E. S.; MARZIALE, M. H. P. Problemas de violência ocupacional em um serviço de urgência hospitalar da cidade de Londrina, Paraná, Brasil. Cad. Saúde Pública, Rio de Janeiro, v. 22, n. 1, p. 217-221, 2006.

GUIMARÃES, L. A. M.; RIMOLI, A. O. "Mobbing" (assédio psicológico) no trabalho: uma síndrome psicossocial multidimensional. Psic.: Teor. e Pesq., Brasília, v. 22, n. 2, p. 183-192, 2006.

HESKETH, K. L. et al. Workplace violence in Alberta and British Columbia hospitals. Health Policy, v. 63, p. 311-321, 2003.

HIRIGOYEN, M. F. Assédio moral: a violência perversa no cotidiano. Rio de Janeiro: Bertrand Brasil, 2000.

IBGE. Pesquisa Assistência Médico Sanitária AMS, 1999. Disponível em: http://w3.datasus.gov.br/ datasus/datasus.php?area=359A1B376C3D0E0F359 G20HIJd3L23M0N\&VInclude=../site/infsaude.php. Acesso em: jun. 2007.

ILO; ICN; WHO; PSI. Framework guidelines for addressing workplace violence in the health sector. GENEVA: ILO, 2002.

KWOK, R. et al. Prevalence of workplace violence against nurses in Hong Kong. Hong Kong Medical Journal, v. 12, n. 1, p. 6-9, feb. 2006.

LEBLANC, M. M.; BARLING, J. Workplace aggression. Current Directions in Psychological Science, v. 13, n. 1, p. 9-12, 2004.
OIT. Un informe de la OIT estudia la salud mental en el trabajo en Alemania, Estados Unidos, Finlandia, Polonia y Reino Unido. Comunicados de prensa 2000, Ginebra, 2000. OIT 37. Disponível em: http://www. ilo.org/global/About_the_ILO/Media_and_public_ information/Press_releases/lang--es/WCMS_008592/ index.htm. Acesso em: maio 2007.

PALÁCIOS, M. et al. Relatório preliminar de pesquisa, violência no trabalho no setor saúde - Rio de Janeiro - Brasil. Instituto de Estudo em Saúde Coletiva, UFRJ. Rio de Janeiro, 2002, 81p., 6 anexos. Disponível em: http://www.iesc.ufrj.br/assediomoral. Acesso em: maio 2007.

PEEK-ASA, C.; RUNYAN, C. W.; ZWERLING, C. The role of surveillance and evaluation research in the reduction of violence against workers. Am. J. Prev. Med., v. 20, n. 2, p. 141-148, 2001.

SCANFONE, L.; TEODÓSIO, A. S. S. Assédio moral nas organizações: novas roupagens para uma antiga temática? E \& G Economia e Gestão, Belo Horizonte, v. 4, n. 7, p. 71-80, jun. 2004.

SOBOLL, L. A. P. Violência psicológica e assédio moral no trabalho bancário. 2007. 214 f. Tese (Doutorado) - Faculdade de Medicina, Universidade de São Paulo, São Paulo, 2007.

TAVARES DOS SANTOS, J. V.; NERY, B.; SIMON, C. A palavra e o gesto emparedados: a violência na escola. Porto Alegre: Secretaria Municipal de Educação, 1999.

WHO. Global consultation on violence and health. Violence: a public health priority. World Health Organisation: Geneva, 1996.

ZALUAR, A.; LEAL, M. C. Violência extra e intramuros. Rev. bras. Ci. Soc., São Paulo, v. 16, n. 45, p. 145-164, 2001. 